University of Nebraska - Lincoln

DigitalCommons@University of Nebraska - Lincoln

Faculty Publications from Nebraska Center for Research on Children, Youth, Families, and Schools

Fall 2011
Children, Youth, Families \& Schools, Nebraska Center for Research on

\title{
Family income, parent education, and perceived constraints as predictors of observed program quality and parent rated program quality
}

\author{
Julia C. Torquati \\ University of Nebraska-Lincoln, jtorquati1@unl.edu \\ Helen Raikes \\ University of Nebraska-Lincoln, hraikes2@unl.edu \\ Catherine Huddleston-Casas \\ University of Nebraska - Lincoln, chuddleston-casas2@unl.edu \\ James A. Bovaird \\ University of Nebraska - Lincoln, jbovaird2@unl.edu \\ Beatrice A. Harris \\ Concord University, Athens, WV, bharris@concord.edu
}

Follow this and additional works at: https://digitalcommons.unl.edu/cyfsfacpub

Part of the Pre-Elementary, Early Childhood, Kindergarten Teacher Education Commons

Torquati, Julia C.; Raikes, Helen; Huddleston-Casas, Catherine; Bovaird, James A.; and Harris, Beatrice A., "Family income, parent education, and perceived constraints as predictors of observed program quality and parent rated program quality" (2011). Faculty Publications from Nebraska Center for Research on Children, Youth, Families, and Schools. 22.

https://digitalcommons.unl.edu/cyfsfacpub/22

This Article is brought to you for free and open access by the Children, Youth, Families \& Schools, Nebraska Center for Research on at DigitalCommons@University of Nebraska - Lincoln. It has been accepted for inclusion in Faculty Publications from Nebraska Center for Research on Children, Youth, Families, and Schools by an authorized administrator of DigitalCommons@University of Nebraska - Lincoln. 


\title{
Family income, parent education, and perceived constraints as predictors of observed program quality and parent rated program quality
}

\author{
Julia C. Torquati, ${ }^{1}$ Helen H. Raikes, ${ }^{1}$ Catherine A. Huddleston-Casas, ${ }^{1}$ \\ James A. Bovaird, ${ }^{1}$ and Beatrice A. Harris ${ }^{2}$ \\ 1. University of Nebraska-Lincoln, Lincoln, NE, USA \\ 2. Concord University, Athens, WV, USA
}

Corresponding author - J. C. Torquati, 135 Mabel Lee Hall, University of Nebraska-Lincoln, Lincoln, NE 68688-0236, USA; tel 402 472-1674, fax 402 472-9170, email jtorquati1@unl.edu

\begin{abstract}
Observed child care quality and parent perceptions of child care quality received by children in poor (below Federal Poverty Line, FPL), low-income (between FPL and $200 \%$ of FPL), and non-low-income families were examined. Observations were completed in 359 center- and home-based child care programs in four Midwestern states and surveys were received from 1313 parents whose children were enrolled in these programs. Multilevel structural equation modeling revealed that programs with higher proportions of low-income families tend to have lower observed quality than programs with a higher proportion of non-low-income families. Programs with more educated parents tended to have better observed quality, however, more educated parents tended to have lower perceptions of quality.
\end{abstract}

Keywords: child care quality, low-income children, poverty, parent perceptions

A minority of all child care programs meet criteria identified as "good" quality, that which is known to support children's development, and child care quality is especially variable for low-income children (Helburn and Howes, 1996; NICHD ECCRN, 2000; Peisner-Feinberg and Burchinal, 1997; Phillips et al., 1994; Raikes et al., 2003). Evidence indicates that low-income children are less likely than their higher-income peers to be enrolled in good quality care (Dearing et al., 2009; Li-Grining and Coley, 2006; Phillips et al., 1994). This difference is likely due to multiple factors such as constraints related to cost; availability or accessibility of good quality care; preferences for a particular type of care; and other family selection factors.

This paper examines the roles of family income, parents' education, parents' perceived constraints in selecting child care, and child care type (family child care, center-based infant care, and center-based preschool care) in predicting observed program quality and parent perceived program quality. For the purpose of this paper, family income is defined using income-to-needs ratio to determine whether families are: (a) poor (at or below the Federal Poverty Level [FPL]; 100\% of poverty); (b) low-income (between $100 \%$ and $200 \%$ of pov- erty); or (c) non-low-income (above $200 \%$ of poverty). These thresholds were selected because the National Center for Children in Poverty has identified families earning $200 \%$ or less of the FPL as low-income, estimating that families above the FPL but earning less than twice the FPL are still not able to meet basic needs. According to the U.S. Census Bureau, the poverty rate for children younger than 18 years old was $18 \%$ in 2007 , and the poverty rate for children younger than 6 years old was $20.8 \%$ (DeNavas-Walt, Proctor, \& Smith, 2008). Forty percent of all children in the United States live in families meeting the low-income or poverty criteria (Gershoff, 2003). In the following review of literature, authors sometimes use the term low-income to refer to poor and/or low-income families, and sometimes to refer to families receiving child care subsidies; however, in all cases low-income never refers to families with income exceeding $200 \%$ of the FPL, and non-low-income refers to families exceeding $200 \%$ of the FPL.

There are several reasons why it is important to examine the quality of child care for poor and low-income children. Good-quality care is consistently associated with more positive social and cognitive development, and poor-quality care

This research was supported by grant 90-YE0011/01 from the U.S. Department of Health and Human Services Administration on Children, Youth, and Families, Child Care Bureau; and the Ewing Marion Kauffman Foundation, Kansas City, Missouri. The contents are solely the responsibility of the authors and do not represent the official views of the funding agency, nor does publication in any way constitute an endorsement by the funding agency. Research reported here was conducted in collaboration with the Midwest Child Care Research Consortium. Principal investigators include Susan Hegland and Carla Peterson, Iowa State University; Jane Atwater and Jean Ann Summers, University of Kansas; Kathy Thornburg, University of Missouri; Carolyn Edwards and Julia Torquati, University of Nebraska. Helen Raikes and Brian Wilcox, University of Nebraska, were project directors. 
is associated with increased behavior problems (Burchinal et al., 1995, 2000, 2008a; McCartney et al., 2007; Peisner-Feinberg et al., 2001; Votruba-Drzal et al., 2004). The NICHD Early Child Care Research Network (ECCRN) reported that quality of care, regardless of type, predicts better vocabulary in fifth grade (Belsky et al., 2007), and higher cognitive-academic achievement and less externalizing behavior at age 15 (Vandell et al., 2010).

Low-income children are more likely to enter kindergarten scoring below their higher-income peers on pre-academic skills (Burchinal et al., 1997; Lee and Burkam, 2002); however, good-quality child care can potentially ameliorate some of the cognitive and social risks for low-income children (Caughy et al., 1994; Dearing et al., 2009; Peisner-Feinberg and Burchinal, 1997; Ramey et al., 2000; Votruba-Drzal et al., 2004, 2010). McCartney et al. (2007) reported effect sizes for the impact of child care quality on school readiness for children living in poverty of $d=.35-.41$; a difference that can increase the probability a child in poverty begins school on a success trajectory.

The associations between family income and quality of child care are complex, in part depending on which indicators of quality are examined. "Structural quality" includes indicators such as caregiver education, child-adult ratio, and group size, while "process quality" refers to aspects of care directly experienced by children such as interactions with caregivers and peers, daily routines, and activities. Some researchers have documented a " $U$ " shaped curve in the relationship between family income and center-based child care quality (NICHD ECCRN, 1997; Phillips et al., 1994; Whitebook et al., 1989). These studies have shown that children at the lowest and highest income levels tend to access better quality care than middle-income children, presumably because lowincome children are targeted by early intervention programs such as Head Start which tend to be of better quality than community-based child care, and higher-income parents are able to buy the best available care in the market (Burchinal et al., 1989; Love et al., 2002; NICHD ECCRN, 1997, 2005; Phillips et al., 1994). Phillips et al. (1994) reported that teachers in community-based centers serving predominantly low-income children were more detached and harsh and less sensitive than teachers in centers serving poorer or more-affluent children, and that quality of care in centers serving upper-income children was the most consistently positive in terms of caregiving and developmentally appropriate activities. Dowsett, Huston, Imes, and Gennetian (2008) reported a curvilinear association between family income and structural quality in center-based programs, but a linear association between family income and process quality. Programs serving primarily low-income children tend to employ teachers with less education and compensate them more poorly than programs serving middle- and upper-income children, and structural indicators of quality are significantly better in programs serving upper-income children (Marshall et al., 2003; Sachs, 2000). Early et al. (2010) reported that pre-kindergarten classes with lower average income-to-needs ratios of enrolled children tended to provide less stimulating learning experiences. Thus, the literature on center-based care leads to expectations for either a linear association with lower-income children in poorer-quality settings or a U shaped curve (with lowest and highest income children receiving the highest quality care).

Fewer studies of family child care have been conducted. One of the most prominent and representative studies of U.S. family child care reported that programs in which poorer children were enrolled were of lower quality on several dimensions including involvement, sensitivity, detachment, and global quality, in comparison to programs serving middleand higher-income children (Kontos, Howes, Shinn, \& Galinsky, 1995). Similarly, Marshall et al. (2003) reported that the quality of family child care homes was significantly poorer for low-income children, and the disparity was particularly striking for the Language-Reasoning and Learning Activities subscales of the Family Day Care Rating Scales (FDCRS; Harms \& Clifford, 1989). The NICHD ECCRN (1997) reported a curvilinear pattern between quality of infant and toddler care and family income for centers, but not homes. Consistent with previous research, we expect to find either a linear or curvilinear association between family income and child care quality.

Associations between family income and quality of child care are also complex because demographic variables such as parent education, marital status, child age, and number of other siblings requiring child care also influence child care use. Selection of center-based care increases with parent education and child age (Ehrle et al., 2001; Fuller et al., 1996; Howes, 1990; Loeb et al., 2004; NICHD ECCRN, 1997; Tout et al., 2001). Mothers with a college degree or more place a greater emphasis on the educational component of care (Johansen, Leibowitz, \& Waite, 1996). One study reported that single mothers rated cost as the most important factor in selecting child care, while married mothers rated child/staff ratio as the most important factor (Leslie, Ettenson, \& Cumsille, 2000). Perhaps most importantly, three studies analyzed data from the NICHD EC$\mathrm{CRN}$ and reported that some of the same family characteristics associated with selecting better-quality child care (i.e., mothers' education, two parents in the home, less traditional parenting values, and White rather than minority ethnicity) are also associated with more optimal child development (Dearing et al., 2009; McCartney et al., 2007; NICHD ECCRN, 2006). However, quality of care still moderated children's developmental outcomes after controlling for family selection effects (Dearing et al., 2009).

Low-income families spend an average of $16 \%$ of their earnings on child care expenses, compared to $6 \%$ in non-poor families, while those below the FPL spend an average of $23 \%$ (Giannarelli and Barsimantov, 2000; Hofferth, 1992). Considering the proportion of income that low-income parents spend on child care, it is not surprising that income is associated with child care use. Low-income mothers are more likely to use their own mothers for child care, and hours of operation and location are more important selection factors than they are for higher-income parents (Cherlin, 1995; Johansen et al., 1996). Center-based care is more frequently used by parents in non-poor families than in low-income families (Capizzano and Adams, 2004; Cherlin, 1995; Ehrle et al., 2001). Relative care is more frequently used by poor $(28 \%)$ and low-income families $(39 \%)$ than by non-low-income families $(23 \%)$, who use nannies more frequently $(8 \%)$ than poor $(1 \%)$ or low-income families (5\%) (Capizzano and Adams, 2004; Cherlin, 1995; Ehrle et al., 2001). Relative care and family child care are often more flexible in terms of part-time and evening care, so parents with non-traditional work hours are more likely to use these informal care arrangements (Meyers \& Jordan, 2006). Poor and lowincome parents experience more constraints (e.g., cost, availability, time, and transportation) on their choices of child care than do non-low-income parents (Collins, Layzer, Kreader, Werner, \& Glantz, 2000). Additionally, good quality child care of any type is in short supply in low-income neighborhoods (Burchinal et al., 2008b; Collins et al., 2000; Tout et al., 2001).

Policies regarding child care tuition subsidy influence parental use of care and providers' willingness to enroll subsidized children. Parents receiving child care subsidies tend to use more formal care, including licensed family child care and center care, than do poor families not receiving subsidies (Burstein and Layzer, 2007; Crosby et al., 2005; Weinraub et al., 2005). Witte and Queralt (2004) found that when reimbursement rates for formal child care subsidy were substantially increased, families were more likely to choose formal 


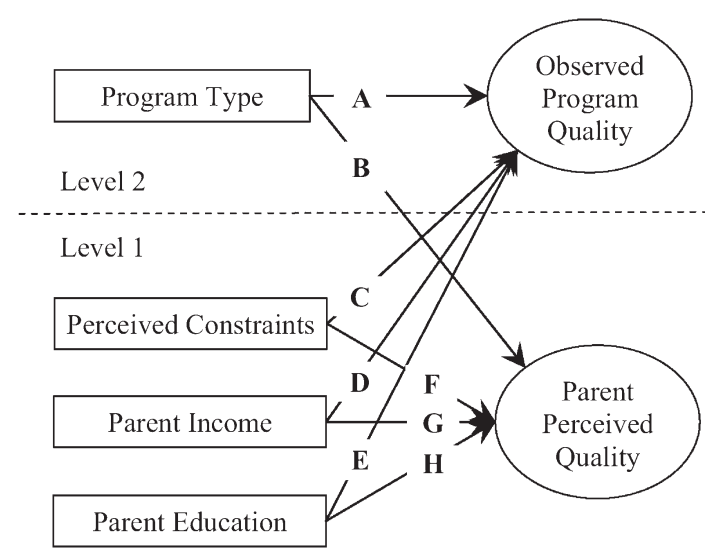

Figure 1. Conceptual model of predictors of parent perceived quality and observed program quality. Ovals represent latent variables and rectangles represent directly measurable variables.

licensed child care. Ryan, Johnson, Rigby, and Brooks-Gunn (in press) reported that families using subsidies chose higherquality care than eligible families who did not use subsidies, and Forry (2009) found that some parents on a wait list for subsidies chose lower-quality care because the cost of better care was prohibitive. Thus, it would appear that child care subsidies increase access to better quality care.

Jones-Branch, Torquati, Raikes, and Edwards (2004) reported better observed quality of care in center-based programs not serving subsidized children and Whitebook, Kipnis, and Bellm (2007) reported higher levels of structural quality (e.g., wages, education, stability) in non-subsidized programs. However, Weinraub et al. (2005) found no differences in quality of care for subsidized and non-subsidized children in a variety of care types (center, family, regulated, unregulated). Child care subsidy may provide access to better quality care, but quality of subsidized programs is variable.

Although there is a modest association between parents' and trained observers' ratings of child care quality, parents tend to rate the quality of their child's early education program better than do trained observers (Cryer and Burchinal, 1997; Cryer et al., 2002). Ratings of parents and observers are most similar for items that are more easily observed. Interestingly, parents tend to give higher ratings to the aspects of care they value most, and the discrepancy between parents and trained observers increases as parents' value of a specific dimension increases. Cryer and Burchinal (1997) reported an inverse association between parent income and their ratings of the quality of their child's care.

\section{Research questions}

This study extends previous research on quality of care for low-income children by using a stratified random sample to examine different types of child care serving poor, low-income, and non-low-income children, using ratings of quality by trained observers and by parents. Because parents are nested within programs, we use multilevel structural equation modeling to test the following research questions (see Figure 1):

1. Are poor and low-income children enrolled in programs that are comparable in quality to their higher-income peers? Consistent with previous research, we expect a positive linear or curvilinear association between income and observed quality. We tested these hypotheses (paths D and G in Figure 1) from income to observed quality and from income to parents' perceptions of quality. We include type of care and parental education in the models because these factors are sometimes associated with parents' choices and quality. Be- cause parent ratings of quality have not been compared as a function of program type, we do not have a directional hypothesis for parent perceived quality (paths A and B). We hypothesize that parents with higher education will have their children enrolled in programs with better observed quality (Cryer \& Burchinal, 1997; paths E and H). Are parents' perceived constraints also associated with their perceptions of child care quality or observed child care quality (paths $\mathrm{C}$ and $\mathrm{F}$ )? Constraints such as transportation, cost, availability of care, and shift work have often been inferred, but have less frequently been directly assessed. We hypothesize that constraints will be inversely associated with both perceived and observed child care quality.

2. Do poor and low-income parents perceive more constraints on their child care choices than non-low-income parents? We hypothesize that poor and low-income parents will report more constraints on their child care choices than will non-low-income parents.

\section{Method}

\subsection{Participants: child care providers and parents}

A stratified random sample of full-day child care programs was drawn from state-level child care licensing and subsidy files in the four states comprising the Midwest Child Care Research Consortium (Nebraska, Iowa, Kansas, and Missouri). The stratification criteria included: (a) state; subsidy/non-subsidy serving programs (programs that had a service agreement to provide care for subsidized children); (b) center-based programs for infants/toddlers and preschool aged children; licensed family homes; (c) registered family homes; (d) license exempt homes (approved to provide care for up to three or four subsidized children, depending on the state); and (e) Early Head Start/Head Start partners. The Gallup Organization drew the stratified random sample and contacted providers by telephone between April and August of 2001. A seven call call-back method was used to ensure the integrity of the random design. The survey response rate for eligible respondents was $81 \%$. The total provider survey sample (teachers or family child care providers) was 2022.

Providers who indicated their willingness to be re-contacted (about $90 \%$ ) were put on a list to be drawn for followup observations. Researchers in each state followed the stratification procedures to draw the observation sample and contacted participants by telephone to invite them to participate in the observation phase of the study. The observation sample included 359 providers (each within separate programs; 112 infant/toddler providers, 114 preschool providers, 133 family child care homes). Providers were selected for observation based on the stratification criteria and received a \$20 gift certificate in appreciation of their participation.

Observed providers were contacted approximately 6 months after being observed and asked to invite the parents of children in their care to participate in a survey. Fifty-three percent of the programs were represented in the parent sample by having parents who returned completed questionnaires. Programs not represented had gone out of business; decided not to distribute questionnaires to parents, or had no parents who returned questionnaires; or had children who changed classrooms within programs or had left the center. Participating parents returned completed surveys in pre-paid envelopes addressed to the Gallup Organization, and \$10 gift cards were then mailed to those parents. One thousand three hundred and twenty-five parents returned surveys, which represents $50 \%$ of parents in the responding programs. Because some items were incomplete, data were available from 1313 parents representing 190 programs. 


\subsubsection{Provider demographics}

The majority of providers were female $(98.8 \%)$ and Caucasian $(81.7 \%)$ while $10.9 \%$ of participants were African American, $4.3 \%$ were Hispanic or Latino, and other ethnic groups each accounted for less than $1 \%$ of the sample. The average age of providers was 38 years $(S D=12.9)$ and the average length of time providers reported being in the early childhood profession was 6.6 years $(S D=2.4)$. Approximately one third of providers $(30 \%)$ reported some coursework or training beyond high school, $8 \%$ had a 1-year child development degree, $17 \%$ had a 2 -year degree, $12 \%$ had a bachelor's degree, $5 \%$ had course work or a degree beyond a BA or BS degree, and 5\% had a degree beyond a bachelor's degree. Thirteen percent had teaching certificates and $17 \%$ had a Child Development Associate (CDA) credential. The average annual earnings reported by all child care providers, adjusted for inflation to 2010 dollars, was $\$ 17,457$. Center-based providers working with preschool-aged children earned the most $(\$ 20,175)$, followed by center-based infant/toddler providers $(\$ 17,877)$, and licensed family child care providers $(\$ 17,223)$. Legally license-exempt providers reported the lowest annual earnings (\$9785).

Analyses were conducted to determine whether providers in the observation sample differed significantly from those who only participated in the survey. Comparing the observation sample to the survey-only sample, observation participants were significantly younger and less experienced, but more educated; more likely to have a teaching certificate, CDA, current CPR and First Aid certification; and to be a member of NAEYC or NAFCC. Observation participants were more likely to report receiving benefits of any kind from their child care employment, and they reported significantly higher earnings. Observation participants were more likely to be Hispanic/Latino, American Indian, or White, and less likely to be Black/African American. Analyses were also conducted to determine whether providers who participated in the parent survey significantly differed from providers who did not. Providers who participated in the parent survey were older on average, more likely to report receiving benefits, and marginally more likely to report more years of experience.

\subsubsection{Family and child demographics}

Family income and size were used to compute income-toneeds ratio of parents to determine poverty $(11.8 \% ; n=151)$, low-income $(15.4 \% ; n=197)$, or non-low-income $(72.8 \% ; n=$ 933) status. More than one fourth $(27.2 \%)$ of the sample met the criteria for poverty or low-income. Seventy-three percent of parents reported that they worked outside the home full time for pay, $15.9 \%$ worked part time, and $7.1 \%$ were not employed. Parents reported working an average of $37.4(S D=8.7)$ hours per week. Parents living in poverty reported working significantly fewer hours per week $(M=33.3, S D=9.1 ; F=14.9)$ than low-income $(M=37.3, S D=7.7)$ or non-low-income parents $(M$ $=37.9, S D=8.7)$. Low-income and in-poverty parents more frequently reported part-time employment and unemployment in comparison to non-low-income parents $\left(\chi^{2}[4, N=1234]=66.3 ; p\right.$ $<.0001)$. Responses to "I work a regular day shift" significantly varied as a function of income $\left(\chi^{2}[2, N=1149]=25.7 ; p<.001\right)$ : $8.4 \%$ of poor, $14.3 \%$ of low-income and $77.3 \%$ of non-low-income parents reported working a regular day shift. Conversely, $33.3 \%$ of poor, $25.8 \%$ of low-income, and $11.4 \%$ of non-low-income parents reported that they worked a regular weekend or evening shift $\left(\chi^{2}[2, N=1038]=47.8 ; p<.001\right)$.

The majority of children in the survey began out-of-home care before 1 year of age $(74.3 \%)$ and $98.9 \%$ by 4 years of age; $51.2 \%$ of children were male. The number of hours in child care per week did not vary by income group (poverty $M$ = 33.4, low-income $M=34.1$, non-low-income $M=33.3 ; F=$ 0.29). Two percent of children were enrolled in Head Start or Early Head Start, and $13.1 \%$ of children were receiving child care subsidy; this included $60.9 \%(n=92)$ of children in pov- erty and $27.9 \%(n=55)$ of low-income children. Overall, $6.1 \%$ of parents reported that their child had been identified as having a developmental problem or special needs; this included $7.9 \%$ of poor children, $9.1 \%$ of low-income children, and $5 \%$ of non-low-income children. The majority (93.6\%) of parents whose children had been identified as having special needs reported that their child was receiving help from early intervention or special education programs.

\subsection{Provider measures}

\subsubsection{Telephone survey}

Child care providers completed a survey designed for this study that took an average of $12.5 \mathrm{~min}$ to complete. Survey questions analyzed in this study included provider demographics and structural and process features of quality.

\subsubsection{Observed program quality}

The Infant/Toddler Environment Rating Scale (ITERS) (Harms \& Cryer, 1990), the Early Childhood Environment Rating Scale-Revised (ECERS-R) (Harms, Clifford, \& Cryer, 1998), and the Family Day Care Rating Scale (FDCRS) (Harms \& Clifford, 1989) were used to assess observed program quality. Trained data collectors conducted an observation of at least two hours to complete each assessment. The ITERS, ECERS-R, and FDCRS provide industry standard measures of child care quality. A score of less than 3 is considered "inadequate" quality, a score between 3 and 5 is defined as "minimal to good" quality, and a score between 5 and 7 is considered to be "good to excellent" quality. The ECERS- $\mathrm{R}$ is a 43-item scale with seven subscales: space and furnishings, personal care, language-reasoning, activities, interaction, program structure, and provisions for parents and staff. The mean score for the current study was $4.44(S D=1.1)$. The ITERS is a similar instrument with 35 items and seven subscales: furnishings and display for children, personal care routines, listening and talking, learning activities, interaction, program structure, and adult needs. The mean ITERS total score for the current study was $4.25(S D=1.0)$. The FDCRS is a $32-$ item measure with six subscales: space and furnishings for care and learning, basic care, language and reasoning, learning activities, social development, and adult needs. The mean FDCRS total score for this study was $4.25(S D=1.3)$. The average total score for each subscale was designated as the Environment Rating Scale Average (ERS), in order to predict observed quality of care in all three contexts (center-based preschool, center-based infant care, and family child care). Although these measures may not be directly comparable, the necessity for a single score representing global quality across ages and settings supports the use of one score; program type is included in the model. All rating scale total scores demonstrated good reliability (ECERS$\mathrm{R} a=.96$; ITERS $a=.93 ;$ FDCRS $a=.96$ ).

\subsubsection{Interactional quality}

Interactional quality was measured by the Caregiver Interaction Scale (CIS; Arnett, 1989) which includes 26 items measuring three qualities of interaction: warmth $(M=3.07 ; S D=0.7$; $a=.94)$; punitive $(M=1.23 ; S D=0.4 ; a=.85)$; and detachment $(M=1.33 ; S D=0.5 ; a=.77)$. Items are rated on a scale from 1 (not at all) to 4 (very much).

\subsubsection{Inter-rater reliability}

Reliability for the environment rating scales (ITERS, ECERS-R, FDCRS) and the CIS was obtained across states by having "gold standard" observers from each state establish minimum reliability with each other, defined as $80 \%$ exact agreement and $85 \%$ agreement within one point. Reliability was established within states by training all observers with the gold standard observers to the same levels (80\% exact, $85 \%$ within one point). Reliability was assessed every 12 observations ( $10 \%$ of the total sample of observations). 


\subsection{Parent measures}

\subsubsection{Parent perceptions of quality}

The parent survey included demographic questions and the Quality of Care from a Parent's Point of View survey (Emlen, Koren, \& Schultze, 2000), which includes 32 items measuring seven aspects of quality (caregiver warmth, learning environment, skilled caregiver, parent and caregiver share information, supportive caregiver, absence of risk factors, and child feelings of safety and security). Parents responded to items on a Likert-type scale ranging from 1 (Strongly Disagree) to 5 (Strongly Agree). These aspects of quality were reduced to four scales for conceptual and empirical reasons. Two strategies were used to construct scales: the seven aspects of quality were examined for conceptual similarity; and we attempted to create scales that would reflect the conceptual basis of the ITERS, ECERS-R, and FDCRS so that dimensions of quality rated by parents and observers would be similar. Parents' perceptions of caregiver warmth toward the child $(M=4.5 ; S D$ $=.49 ; a=.85)$, learning activities in the program $(M=4.4 ; S D$ $=0.6 ; a=.83)$, and their own relationship with the caregiver $(M=4.4 ; S D=0.6 ; a=.71)$ assess positive dimensions of quality. Initially, two scales assessing harshness in the caregiverchild relationship and negative practices (e.g., too much TV and concerns about health and safety) were constructed, but they were highly correlated so we combined them into a single scale assessing negative practices $(M=1.5 ; S D=0.6 ; a=.76)$.

\subsubsection{Parent perceptions of constraints on child care choices}

Parents rated seven items assessing potential constraints on child care choices (e.g., "the cost of child care has prevented me from getting the kind of care I want") on a scale from $1=$ Strongly Disagree to 5 = Strongly Agree. Descriptive statistics are presented in Table 1.

\section{Results}

Our first research question concerned whether children in poor and low-income families are enrolled in programs comparable in quality to their non-low-income peers. The nested nature of the data and the presence of latent variables (quality) required that a multilevel structural equation model be used (MSEM; Bovaird, 2007). The multivariate model evaluating the differences in observed and perceived program quality based on family income level was tested conditional upon the levels of perceived constraints on child care arrangements, type of program, and parent education.

\subsection{Multilevel modeling, centering, and contrasts}

Multilevel modeling with parents nested within programs was used to test the conceptual model presented in Figure 1. Mplus version 5.0 (Muthen \& Muthen, 1998-2008) was used to estimate the hypothesized model using full information maximum likelihood (FIML) for dealing with missing data, multilevel modeling with latent variables, and conducting a multilevel model with unbalanced within-program sample sizes. All within-program predictor variables were group-mean-centered prior to entry into the model to prevent level 2-variance from confounding level-1 effects. Within-program averages/aggregates of all within-program predictor variables were entered as between-program effects and a between-program measurement model for all within-program latent variables was included in order to test for micro-macro situations where within-level variables are hypothesized to predict between-level outcomes (Croon \& van Veldhoven, 2007). This is also done to prevent the occurrence of an ecological or atomistic fallacy (Bovaird, 2007).

Within-program (level 1) variables included a parent-perceived quality latent variable measured by learning activities, the provider-child relationship, the provider-parent relation- ship, and negative practices from the Quality of Care from a Parent's Point of View measure. Mean and standard deviations for the parent-perceived quality measures by family income level and program type are reported in Table 2. Parent income was operationalized as a 3 -level categorical variable $(1=$ poverty, 2 = low-income, 3 = non-low-income) and represented by two dummy-coded contrast variables comparing (a) families below the poverty level with non-low-income families $(\mathrm{C} 1: 1=$ $1,2=0,3=0$ ) and (b) low-income families and non-low-income families $(\mathrm{C} 2: 1=0,2=1,3=0)$. Parent education was operationalized as a pseudo-continuous variable with seven levels ranging from less than a high school diploma to graduate school degree. The family-level (within-program) constraint variables were group-mean-centered as well. Correlations among all within-program variables are reported in Table 3.

Between-program (level 2) variables included an observed program quality latent variable measured by warmth and detachment from the CIS and a mean environment rating scale score. The punitive subscale did not have sufficient variance to include in the analysis. Means and standard deviations for the observed program quality measures by family income level and program type are also reported in Table 2. An average parent-perceived quality latent variable (PPQ) measured by the within-program averages of the same four variables listed above was also included. The average levels of parent education and income for all parents with children attending a given program were included as the mean of the level-1 variable within each program. Type of program was operationalized as a three-level categorical variable $(1=$ infant center, $2=$ licensed family, 3 = preschool center) and represented by two dummy variables contrasting (a) infant centers vs. preschool centers, and (b) licensed family centers vs. preschool centers, where preschool centers always represent the comparison group. The within-program (family-level) average of each constraint variable was entered as between-program variables. Correlations among all between-program variables are reported in Table 4.

\subsection{MSEM of perceived program quality}

Table 5 reports parameter estimates $(B)$, the standardized solution $(\beta)$, and standard errors $(S E)$ for all estimated model parameters. The model path diagram is presented in Figure 2 , with darker paths indicating effects that were statistically significant at the $a=.05$ level. The overall model achieved close fit, $\chi^{2}(105)=297.135, p<.05 ;$ CFI = .929; RMSEA = .038; $\mathrm{SRMR}_{\text {Within }}=0.008, \mathrm{SRMR}_{\text {Between }}=0.043$. Three deviations from the conceptual model in Figure 1 were necessary for model stability, and the inclusion of each resolved an estimation error. A residual correlation between measures of the provider-parent relationship and negative practices was added at the within-facility level, a residual correlation between the average environment ratings and learning activities was added at the between-facility level, and observed program quality was allowed to predict parent-perceived quality at the between-facility level. While the Comparative Fit Index (CFI) was just outside the guidelines proposed by $\mathrm{Hu}$ and Bentler (1999), all other measures of approximate fit are well within acceptable guideline ranges, especially the RMSEA.

At the within-program level, parental income (path " $\mathrm{G}$ " in Figure 1) was not associated with parents' perceptions of program quality. Within a group of parents with children attending the same program, parents with higher levels of education (path " $\mathrm{H}$ " in Figure 1) tended to have lower perceptions of the quality of their child care program $(\beta=-0.07, p<$ $.05)$. Four of the seven perceived constraints significantly predicted parent perceptions of quality. Within a group of parents with children attending the same program, the more the parent perceived the cost of child care as prohibitive and the more difficulty a parent had in finding a facility they wanted, the lower the parent perception of program quality $(\beta=-0.20$, $p$ 
Table 1. Parent perceptions of constraints on child care choices as a function of family income and type of program, controlling for parent education.

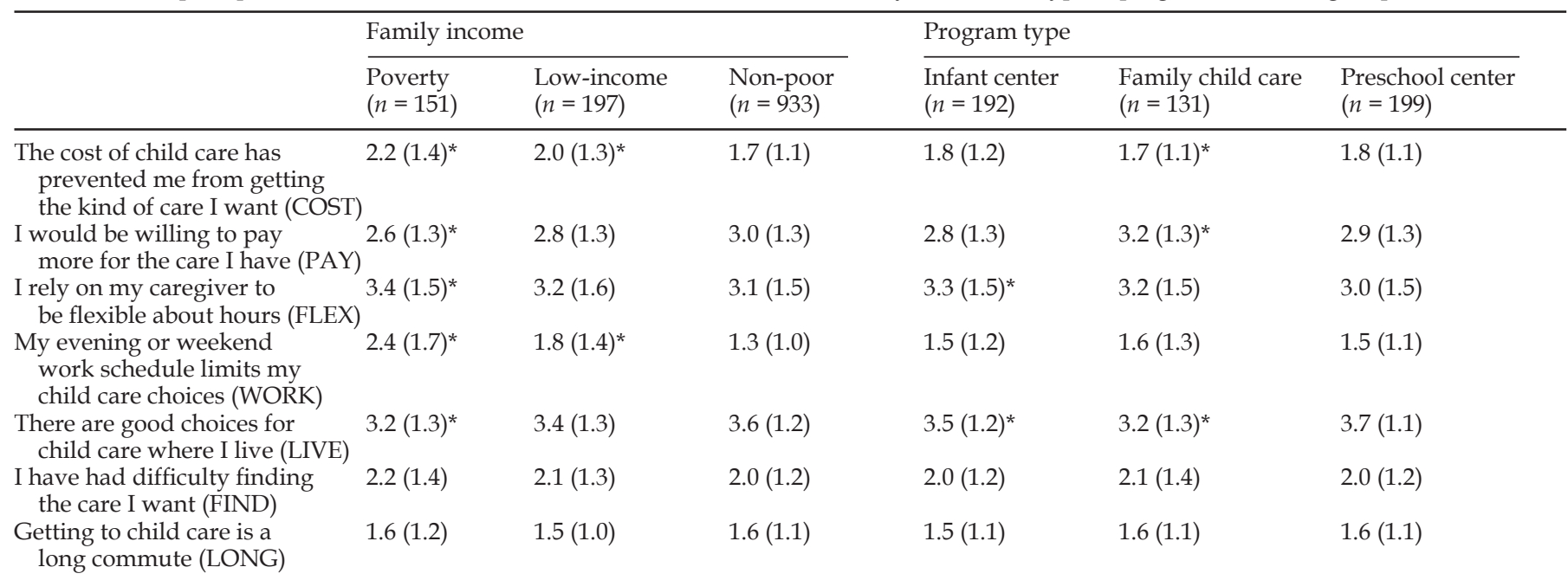

Response scale ranged from 1 (Disagree Strongly) to 5 (Agree Strongly). Family income contrasts were poverty (or low-income) vs. non-lowincome, and program type contrasts were infant center (or family child care) vs. preschool center.

* A priori planned contrast was significant at the $p<.05$ level.

Table 2. Mean (standard deviation) observed program quality and parent perceptions of quality as a function of family income and type of program.

\begin{tabular}{|c|c|c|c|c|c|c|}
\hline & \multicolumn{3}{|c|}{ Family income } & \multicolumn{3}{|l|}{ Program type } \\
\hline & $\begin{array}{l}\text { Poverty } \\
(n=151)\end{array}$ & $\begin{array}{l}\text { Low income } \\
(n=197)\end{array}$ & $\begin{array}{l}\text { Non-poor } \\
(n=933)\end{array}$ & $\begin{array}{l}\text { Infant center } \\
(n=192)\end{array}$ & $\begin{array}{l}\text { Family child care } \\
(n=131)\end{array}$ & $\begin{array}{l}\text { Preschool center } \\
(n=199)\end{array}$ \\
\hline
\end{tabular}

The ERS scoring metric ranges from 1 to 7 , the CIS scoring metric ranges from 1 to 4 ; and parent perceive quality is rated on a metric from 1 to 5 (all metrics scored from low to high).

Table 3. Within-program correlations (Level 1: parents).

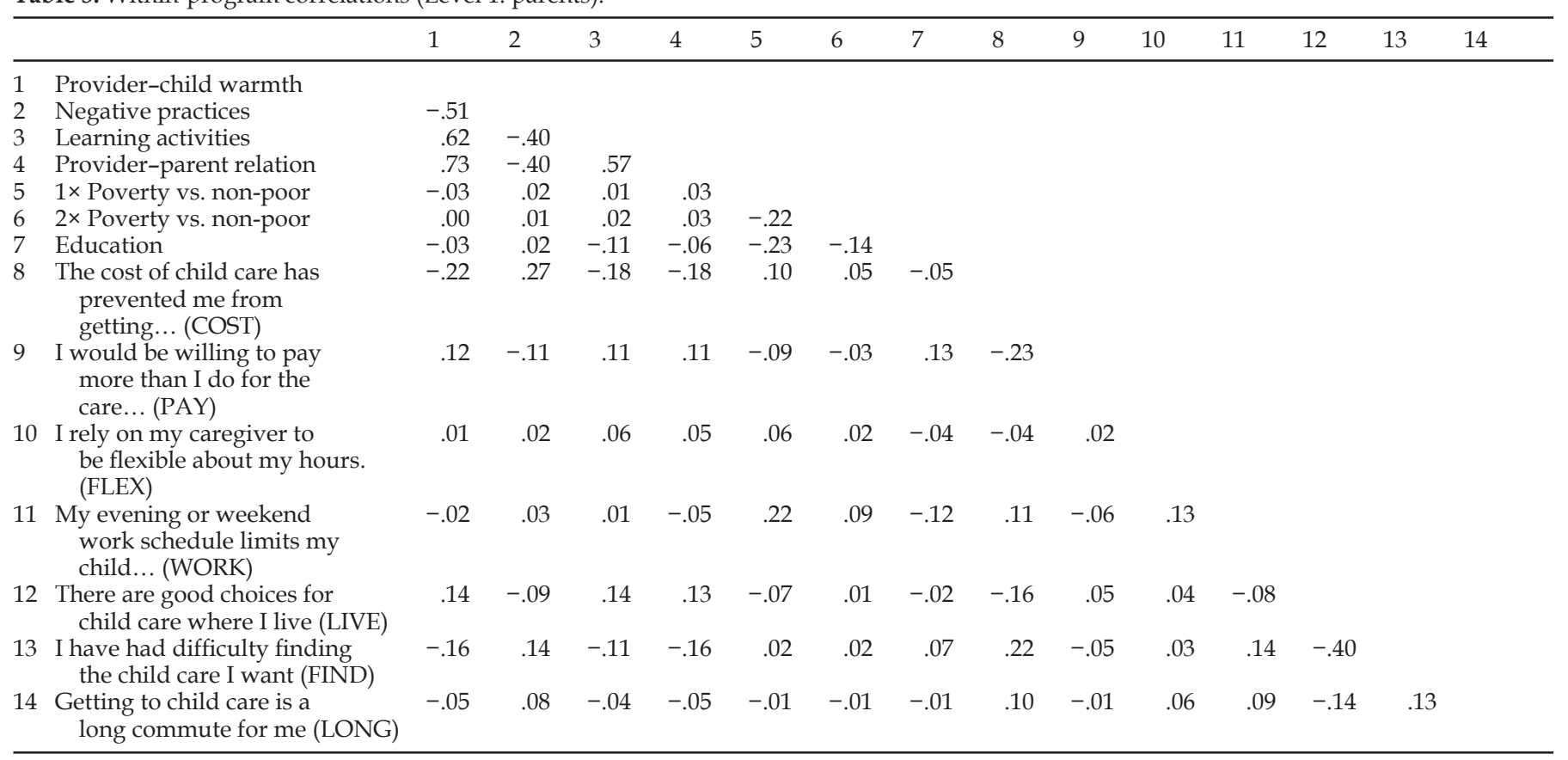


Table 4. Between-program correlations (Level 2: programs).

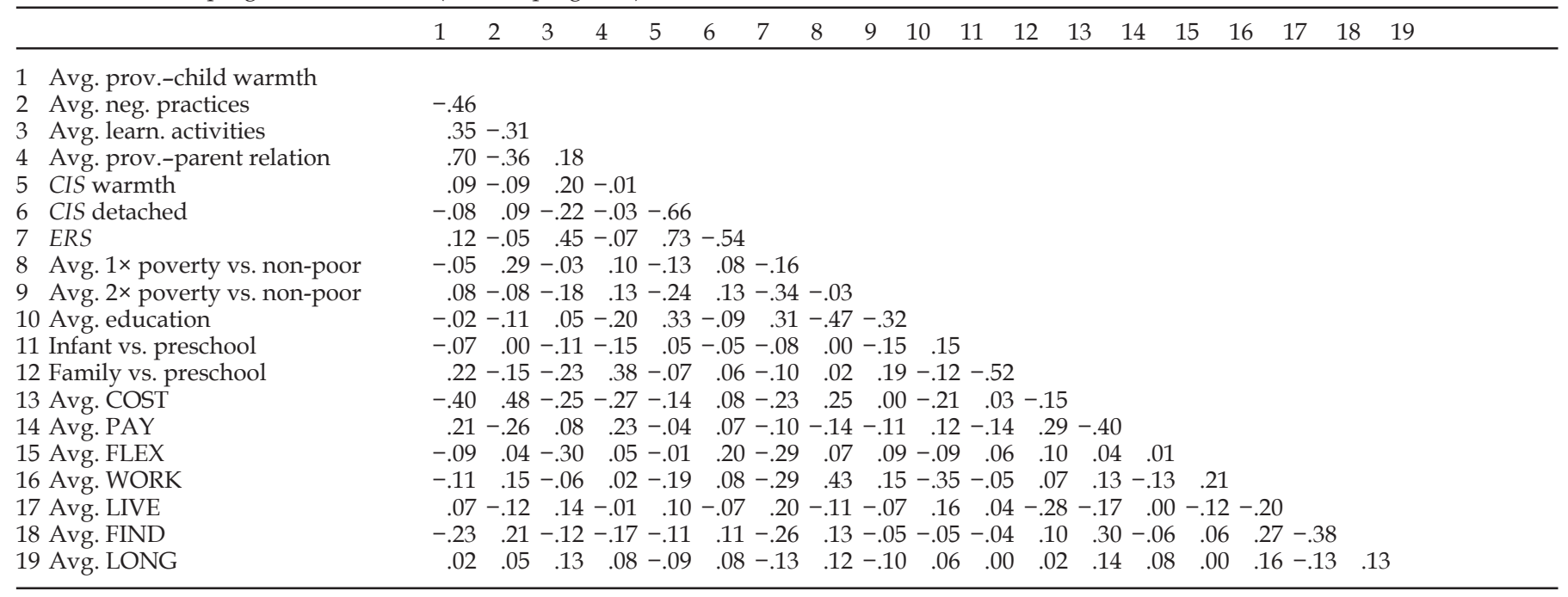

Table 5. MSEM parameter estimates (B), standardized solution $(\beta)$, and standard errors (SE).

\begin{tabular}{|c|c|c|c|c|c|c|c|c|}
\hline & \multicolumn{4}{|c|}{ Within-program } & \multicolumn{4}{|c|}{ Between-program } \\
\hline & $B$ & $\beta$ & $S E$ & & $B$ & $\beta$ & $S E$ & \\
\hline \multicolumn{9}{|l|}{ Factor loadings } \\
\hline Provider-child warmth (PTW) & 1.04 & 0.88 & .04 & * & 1.04 & 0.85 & .04 & * \\
\hline Negative practices (NP) & -0.78 & -0.58 & .04 & * & -0.78 & -0.44 & .04 & * \\
\hline Learning activities (LA) & 1.00 & 0.69 & - & _- & 1.00 & 0.50 & - & _- \\
\hline Provider-parent relationship (CRP) & 1.25 & 0.83 & .05 & * & 1.25 & 0.80 & .05 & * \\
\hline \multicolumn{9}{|l|}{ Observed program quality } \\
\hline CIS detached (CISD) & & & & & -0.52 & -0.66 & .07 & * \\
\hline ERS average (ERS) & & & & & 1.07 & 0.72 & .18 & * \\
\hline \multicolumn{9}{|l|}{ Path coefficients } \\
\hline \multicolumn{9}{|l|}{ Parent perceptions of program quality } \\
\hline Observed program quality & & & & & 0.04 & 0.13 & .02 & $\ddagger$ \\
\hline Poor vs. non-low & 0.02 & 0.02 & .04 & & 0.04 & 0.04 & .08 & \\
\hline Low vs. non-low & 0.02 & 0.01 & .03 & & 0.06 & 0.06 & .08 & \\
\hline FLEX & 0.01 & 0.02 & .01 & & -0.03 & -0.08 & .03 & \\
\hline WORK & -0.00 & -0.01 & .01 & & -0.03 & -0.07 & .03 & \\
\hline LIVE & 0.04 & 0.09 & .01 & * & 0.01 & 0.04 & .03 & \\
\hline FIND & -0.04 & -0.10 & .01 & * & -0.05 & -0.12 & .03 & $\neq$ \\
\hline LONG & -0.01 & -0.02 & .01 & & 0.06 & 0.18 & .03 & $*$ \\
\hline \multicolumn{9}{|l|}{ Observed program quality } \\
\hline Poor vs. non-low & & & & & 0.18 & 0.05 & .31 & \\
\hline Low vs. non-low & & & & & -0.73 & -0.18 & .31 & * \\
\hline Parent education & & & & & 0.19 & 0.27 & .07 & * \\
\hline Infant vs. preschool & & & & & -0.06 & -0.04 & .13 & \\
\hline Family vs. preschool & & & & & 0.01 & 0.00 & .13 & \\
\hline COST & & & & & -0.13 & -0.11 & .10 & \\
\hline PAY & & & & & -0.18 & -0.15 & .10 & $\ddagger$ \\
\hline FLEX & & & & & 0.07 & 0.05 & .11 & \\
\hline
\end{tabular}

* Statistical significance at the $p<.05$ level.

$\ddagger$ Marginal significance in the $.05<p<.10$ range.

$<.05$, and $\beta=-0.10, p<.05$, respectively). The more the parent was willing to pay for child care and the more the parent perceived that there are good choices in their area, the higher the parent perception of the quality of the program their child attends $(\beta=0.10, p<.05$, and $\beta=0.09, p<.05$, respectively) Caregiver flexibility, evening or weekend work schedules, and commuting distance did not significantly predict parent perceptions of program quality (see Table 5). 


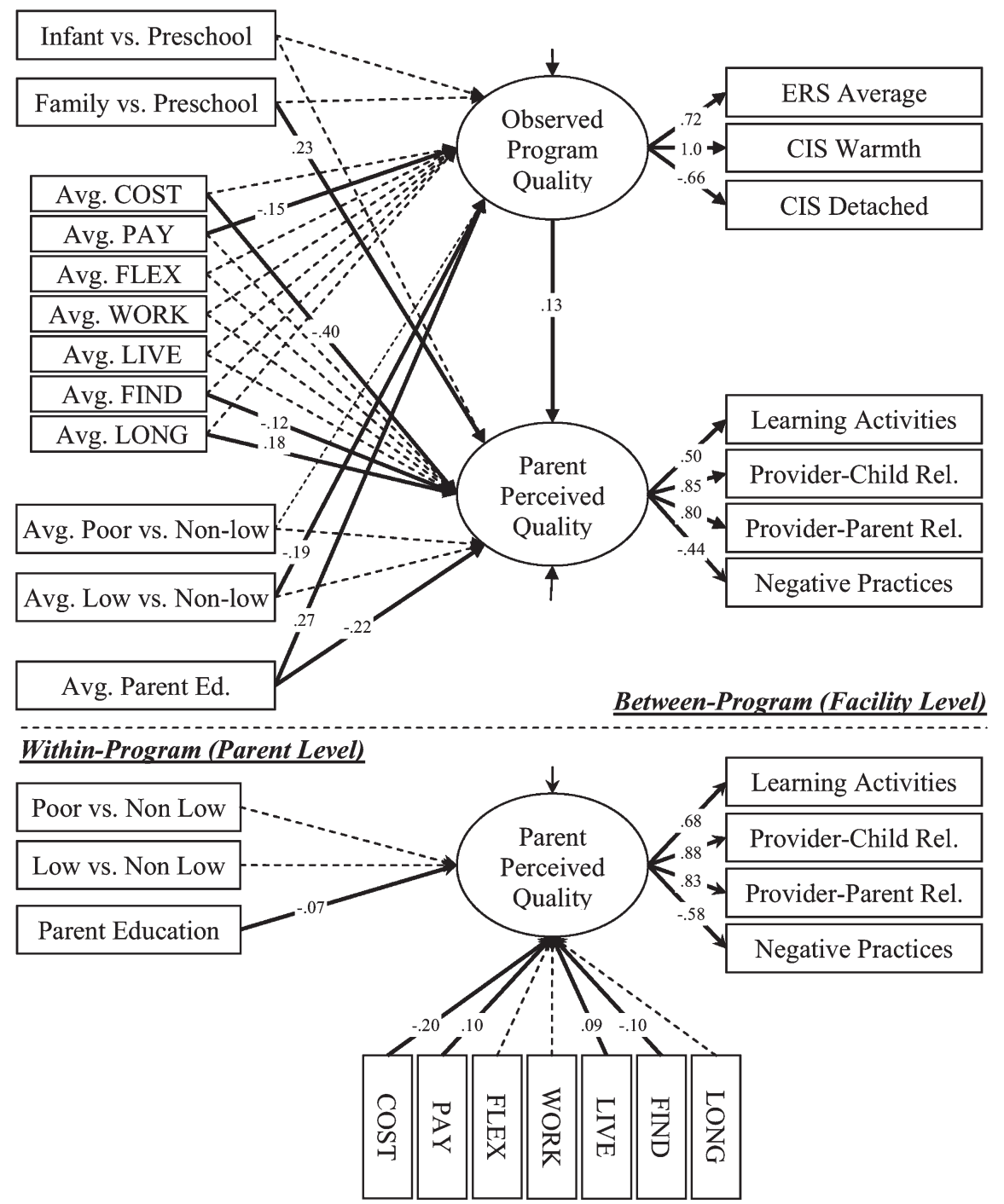

Figure 2. Path diagram and partial standardized solution for Analysis 2. Notes: Dashed paths indicate paths that were not statistically significant at the $p<.05$ level. Solid paths indicate statistical significance at the $p<.05$ level or marginal significance in the $.05<p<.10$ range, as reported in Table 5 .

At the between-program level, programs with higher proportions of families who are low-income (path " $\mathrm{D}$ " in Figure 1) tended to have lower ratings of observed quality than programs with a higher proportion of non-low-income parents $(\beta$ $=-0.18, p<.05)$. Program type (path " $\mathrm{A}$ " in Figure 1) did not significantly predict observed program quality, but parents perceived licensed family child care programs (path " $B$ " in Figure 1) as higher in quality than preschool centers $(\beta=0.23$, $p<.05)$. Programs with parents of higher educational status (path " $E$ " in Figure 1) had better observed quality on average $(\beta=0.27, p<.05)$. In addition, programs with more educated parents had lower average parent perceptions of program quality $(\beta=-0.23, p<.05)$.

Two of the seven average perceived constraints were statistically significant predictors of average parent perceptions of program quality (path " $F$ " in Figure 1), while none of the constraints were significant predictors of observed program quality (path " $C$ " in Figure 1). Programs with parents who found costs more prohibitive on average had lower average parent perceptions of quality $(\beta=-0.40, p<.05)$, and programs with parents who had a longer average commute to the program had higher average parent perceptions of quality $(\beta=0.18, p<.05)$. Programs with parents who had more difficulty, on average, finding the care they want had marginally lower average parent per- ceptions $(\beta=-0.12, p=.09)$, and programs with parents who were willing to pay more for child care on average, had marginally lower observed program quality $(\beta=-0.15, p=.06)$.

Finally, the prediction of parent-perceived quality by observed program quality at the between-facility level was marginally significant $(\beta=0.13, p=.09)$ with higher-quality programs being perceived as higher quality on average. The strong and significant between-program residual correlation between environmental rating and parent-perceived learning activities $(r=.49)$ indicates a positive relationship beyond what is accounted for by parent and observed perceptions of quality. Perhaps ratings of a program overall are especially tied to the quality of learning activities provided by the program. The small but statistically significant within-program residual correlation between the perception of provider-parent relationship and negative practices $(r=.19)$ is largely due to the within-facility sample size and too small to be of consequence, despite its necessity for model stability.

\subsection{Parent perceptions of constraints on child care choices}

We compared parents' perceptions of constraints on child care arrangements as a function of poverty, low-income, and non-low-income status. Parent education and type of care are 
included in the models because of their potential associations with income and quality. The second question involved nested data without latent variables. There were also seven outcomes creating a multiplicity concern so we used a multivariate multilevel model with a priori planned comparisons.

Seven items assessing constraints on child care choices were compared via a multivariate multilevel model with parents nested within programs to test the hypothesis that poor and low-income parents would report more constraints on their child care choices compared to non-low-income parents. Parent education and type of care were included as covariates because they are also factors that can influence constraints. As hypothesized, poor and/or low-income parents rated five of the seven constraints higher than did non-lowincome parents. A priori planned contrasts indicated that: poor parents were less likely than non-low-income parents to report that there are good choices for child care where they live; poor parents were most likely to report that their evening or weekend work schedule limited their child care choices, and non-low-income parents were least likely to report this constraint; poor parents were more likely than nonlow-income parents to report that they rely on their caregiver to be flexible about hours; poor and low-income parents were both more likely than non-low-income parents to report that the cost of child care prevented them from obtaining the kind of care they want for their child; and non-low-income parents were more likely than poor parents to indicate that they would be willing to pay more than they do for child care. While there was no difference between low-income and nonlow-income parents in terms of willingness to pay more, parents in programs with a higher proportion of low-income parents were less likely to report a willingness to pay more for their child care, on average. Parent ratings of difficulty finding the care they want or having a long commute did not significantly differ by income. Parents with higher education levels were more willing to pay more for their current child care and reported having more difficulty finding the care they want for their child.

Parent rating of constraints varied by type of child care program. Parents with children in family-based child care were less likely than parents with children in preschool to report that the cost of child care prevented them from obtaining the kind of care they want. Parents with children in family-based child care were more likely than parents with children in preschool to indicate that they would be willing to pay more than they do for child care. Parents with children in infant centers were more likely than parents with children in preschool to report that they rely on their caregiver to be flexible about hours. Parents with children in infant centers and family-based child care were both less likely than parents with children in preschool to report that there are good choices for child care where they live. Results are presented in Table 1.

\section{Discussion}

This paper examined the quality of child care received by poor, low-income, and non-low-income children in a stratified random sample in four Midwestern states that included homes and centers, licensed and legally license exempt programs, and programs that received subsidy and that did not. Multilevel structural equation modeling was used to examine family income, parent education, and parent perceptions of constraints on child care accessibility as predictors of quality assessed by trained observers and by parents. Parents' reports of constraints on the accessibility of child care were also compared by income level as predictors of observed and perceived quality, in order to contextualize the dynamics of child care selection within constraints.

\subsection{Family income, parents' perceptions of quality, and ob- served quality}

Within a group of parents whose children attended the same program, parental income did not predict parents' perceptions of quality; however, programs with higher proportions of families who were low-income tended to have lower observed quality than programs with a higher proportion of non-low-income parents. There was no significant difference in observed quality of programs serving poor children and those who were non-low-income, indicating that for this sample, children in low-income families received the poorest quality of care. These results document continuing inequity in access to quality of care for low-income children, in this study defined as those living in families between $100 \%$ and $200 \%$ of the FPL. These results are consistent with other studies documenting a " $U$ " shaped curve in the associations between family income and child care quality, with the caveat that previous studies have variously defined low, middle, and higher-income families (e.g., Dowsett et al., 2008; NICHD ECCRN, 2000; Phillips et al., 1994).

\subsection{Parent education, perceptions of quality, and observed quality}

Consistent with previous research, programs with more highly educated parents on average tended to have higher observed quality (Cryer and Burchinal, 1997; McCartney et al., 2007; NICHD ECCRN, 2006). However, more highly educated parents tended to have lower perceptions of quality than parents in the same program with a lower level of educational attainment. This is consistent with findings reported by Cryer and Burchinal (1997) and suggests that more educated parents are potentially more discerning in their evaluation of child care programs.

Constraints on child care choices such as work schedules, location, and cost have often been inferred. Poor and low-income parents in this study reported more constraints on their child care choices than did non-low-income parents. For example, poor and low-income parents were more likely than non-low-income parents to indicate that their work schedule limits child care choices, and separate analysis of work schedules as a function of income indicated that non-low-income parents were most likely to work a regular day shift while poor parents were most likely to work an evening or weekend shift, times when it may be more difficult to access quality child care. MSEM analyses indicated that parent-reported constraints of prohibitive cost and difficulty finding care predicted lower perceptions of quality, while parents who were more willing (or able) to pay more and who reported good child care choices where they live perceived the quality of their program to be higher. However, parent-reported constraints did not predict observed quality.

Observed program quality marginally predicted parents' perceptions of program quality, indicating that parents who rated their child's program more positively tended to be in programs that were of better quality. Previous research has found that parents tend to rate child care quality more favorably than do trained observers (Cryer and Burchinal, 1997; Cryer et al., 2002). Although our primary purpose was not to compare parents' and observers' ratings of quality, these results indicate that while parents' and observers' ratings are related in a linear fashion, the effect size of the association suggests that there is limited congruence. Interestingly, we found a strong and significant between-program residual correlation between observers' average environmental rating and parent-perceived learning activities that indicates a positive relationship beyond what is accounted for by parent and 
observed perceptions of quality. There are several possible explanations for this association. First, it is possible that observer ratings of a program overall are especially tied to the quality of learning activities provided by the program. Second, learning activities may carry more weight than other program aspects that influence parents' perceptions of quality. Finally, insofar as the quality of learning activities as measured by the Environment Rating Scales involves a certain level of intentionality on the part of early childhood professionals, perhaps programs with professionals who are more intentional about learning activities are more intentional across the board in terms of their practices, resulting in better observed quality.

\subsection{Limitations}

Data for this study were collected from four Midwestern states and therefore may not generalize to other regions of the U.S. Data were collected in 2001, and changes in child care policies and contexts may limit current applicability of findings. Public pre-kindergarten (pre-k) has expanded in two of the four states, which could potentially increase access to good quality care for poor and low-income children. Eligibility for child care subsidy has become much more restrictive in one state (from $185 \%$ of poverty to $125 \%$ of poverty), potentially limiting access to quality care for low-income children. With respect to quality of child care, two subsequent studies conducted in the same four states since these data were collected yielded similar or lower means on the Environment Rating Scales, indicating that it is unlikely that the modal level of quality available has changed substantially. With respect to the economic context, the child poverty rate has risen significantly since 2000. Overall, more children are living in poverty, fewer children are eligible for subsidy, more public pre-k is available, and evidence indicates that overall quality has not improved (DeNavas-Walt et al., 2008).

Low parent participation rates also limit generalizability. Families were recruited from a stratified random sample of programs but only $53 \%$ of programs participated in the parent survey, and $50 \%$ of parents in the programs responded resulting in a response rate of approximately $25 \%$; thus, the sample of parents is not representative. Typically, programs of lower quality are less likely to participate in research and this may result in over-estimating the level of quality care available. It is possible that the most engaged or satisfied parents participated in the study, which would also over-estimate measurement of parent perceptions of quality.

Publicly funded pre-k programs were not examined in this study, and it is possible that good quality pre-k can increase access to quality care and education for poor and low-income children. States vary in terms of income eligibility criteria and standards of quality, so it is not clear how availability of public pre-k might change associations between family income and child care quality. Pre-k programs also do not consistently meet levels of quality sufficient to promote children's development (Burchinal et al., 2008a; LoCasale-Crouch et al., 2007). Of particular concern is a finding that the lowest quality pre-k classroom profile was associated with classroom poverty level, indicating that children who are most educationally vulnerable due to poverty are least likely to receive the levels of instructional and emotional support to moderate their risk (LoCasale-Crouch et al., 2007; Pianta et al., 2005). States with restrictive eligibility for pre-k (children at FPL or below) may increase access to quality for poor, but not low-income children, and therefore not address the fact that low-income children tend to be in the lowest quality care, on average. It is unlikely that the availability of public pre-k has a substantial impact on the quality of community child care.

\subsection{Contributions}

This research makes several distinct contributions to understanding the complex associations between family income, parent-perceived constraints, parent education, and observed child care quality. A particular strength of this study is that we examined both observed quality and parent perceptions of quality in the same sample. In addition, we used parent-reported family income and size to determine family economic status, rather than proxy variables such as neighborhood, subsidy, or director-reported assessments of average family income, which is important because programs often serve families of varying income levels and this permitted us to make within-program as well as between-program comparisons. We distinguished between families living at or below the poverty level and those who are low income but who are less likely to qualify for programs such as Head Start or child care subsidy and these distinctions have implications for policies aiming to improve access to quality for poor and lowincome children. Sampling a diverse array of programs representing choices available to parents maximizes external validity of results. This study included children enrolled in family child care homes and centers, licensed and legally license exempt programs, and programs serving children whose tuition is subsidized and those that do not.

The complexity of research questions regarding availability and selection of quality child care, family constraints, and income require sophisticated analytic methods to better illuminate these associations. Multilevel structural equation modeling and nested data allowed us to make within-program comparisons as a function of family income and parental education as well as between-program comparisons, and these analyses are well suited to disentangling the complexity of the associations between the demographic variables and child care quality.

\subsection{Conclusions and implications}

The current study makes several contributions. It highlights the particular difficulty of accessing quality child care for families with incomes between $100 \%$ and $200 \%$ of poverty, a finding first reported nearly 15 years ago, but one which, despite increased investments in quality and subsidy, has not improved. This study verifies the perceived constraints reported by poor and low-income parents and begins to disentangle the complex relations among income, parent education, perceived constraints, perceived quality, and observed quality. Child care selection is a complex process that involves family and parent resources, constraints, and selection among programs available in the proximal community. Family income is a significant predictor of observed program quality in the present study, possibly because low-income parents do not access enrichment programs such as Head Start/Early Head Start as frequently as poor families, and likely because they are unable to purchase the best quality of care available in the market as non-low-income parents are able to do. Taken together, these results indicate that both parent education and family income are resources that can be leveraged to access better quality child care. However, policies should more directly target families without such resources to enable them to access better quality care. For example, linking quality standards to program subsidy receipt or incentivizing the choice of better quality programs for families participating in subsidy programs may increase access to better quality care and education. Particular attention must be paid to low-income children and families who may not currently qualify for state or federally funded programs, but who also do not have the means to purchase good qual- 
ity child care. Equity remains out of our grasp but we must keep reaching by investigating ways to increase access for children and families who lack these resources.

\section{References}

Arnett, 1989 • J. Arnett, Caregivers in day-care centers: Does training matter?. Journal of Applied Developmental Psychology, 10 (1989), pp. 541-552.

Belsky et al., $2007 \bullet$ J. Belsky, D. L. Vandell, M. Burchinal, K. A. Clarke-Stewart, K. McCartney, and M. Tresch Owen, et al. Are there long-term effects of early child care?. Child Development, 78 (2007), pp. 681-701.

Bovaird, $2007 \bullet$ J. A. Bovaird, Multilevel structural equation models for contextual factors, T. D. Little, J. A. Bovaird, N. A. Card, Editors, Modeling contextual effects in longitudinal studies, Erlbaum, Mahwah, NJ (2007).

Burchinal et al., 1997 - M. R. Burchinal, F. A. Campbell, D. M. Bryant, B. H. Wasik, and C. T. Ramey, Early intervention and mediating processes in cognitive performance of children of low-income African American families. Child Development, 68 (1997), pp. 935-954.

Burchinal et al., 2008a • M. Burchinal, C. Howes, R. Pianta, D. Bryant, D. Early, and R. Clifford, et al. Predicting child outcomes at the end of kindergarten from the quality of pre-kindergarten teacherchild interactions and instruction. Applied Developmental Science, 123 (2008), pp. 140-153.

Burchinal et al., $1989 \bullet$ M. Burchinal, M. Lee, and C. Ramey, Type of day-care and preschool intellectual development in disadvantaged children. Child Development, 601 (1989), pp. 128-137.

Burchinal et al., 2008b • M. Burchinal, L. Nelson, M. Carlson, and J. Brooks-Gunn, Neighborhood characteristics and child care type and quality. Early Education and Development, 19 (2008), pp. 702-725.

Burchinal et al., $1995 \bullet$ M. R. Burchinal, S. L. Ramey, M. K. Reid, and J. Jaccard, Early child care experiences and their association with family and child characteristics during middle childhood. Early Childhood Research Quarterly, 10 (1995), pp. 33-61.

Burchinal et al., $2000 \bullet$ M. R. Burchinal, J. E. Roberts, R. Riggins, S. A. Zeisel, E. Neebe, and D. Bryant, Relating quality of center-based child care to early cognitive and language development longitudinally. Child Development, 71 (2000), pp. 339-357.

Burstein and Layzer, 2007 • N. Burstein and J. I. Layzer, Patterns of child care use among low-income families: Final report, (2007), Retrieved from http://www.acf.hhs.gov/programs/opre/cc/nsc low income/index.html

Capizzano and Adams, $2004 \bullet \mathrm{J}$. Capizzano and G. Adams, Children in low-income families are less likely to be in center-based child care (Snapshots of America's Families III No. 16), (2004), Retrieved from http:/ / www.urban.org/publications/310923.html

Caughy et al., $1994 \bullet$ M. O. Caughy, J. A. DiPietro, and D. M. Strobino, Day-care participation as a protective factor in the cognitive development of low-income children. Child Development, 65 (1994), pp. 457-471.

Cherlin, 1995 • A. J. Cherlin, Policy issues of child care, P. L. ChaseLansdale, J. Brooks-Gunn, Editors, Escape from poverty: What makes a difference for children?, Cambridge University Press, New York, NY (1995), pp. 121-137.

Collins et al., $2000 \bullet$ A. M. Collins, J. I. Layzer, J. L. Kreader, A. Werner, and F. B. Glanz, National study of child care for low-income families: State and community substudy interim report, Abt Associates, Washington, DC (2000).

Croon and van Veldhoven, $2007 \bullet$ M. A. Croon and M. J. P. M. van Veldhoven, Predicting group-level outcome variables from variables measured at the individual level: A latent variable multilevel model. Psychological Methods, 121 (2007), pp. 45-57.

Crosby et al., 2005 • D. A. Crosby, L. Gennetian, and A. Huston, Child care assistance policies can affect the use of center-based care for children in low-income families. Applied Developmental Science, 92 (2005), pp. 86-106.

Cryer and Burchinal, $1997 \bullet$ D. Cryer and M. Burchinal, Parents as child care consumers. Early Childhood Research Quarterly, 12 (1997), pp. 35-58.

Cryer et al., 2002 - D. Cryer, W. Tietze, and H. Wessels, Parents' perceptions of their children's child care: A cross-national comparison. Early Childhood Research Quarterly, 17 (2002), pp. 259-277.

Dearing et al., $2009 \bullet$ E. Dearing, K. McCartney, and B. A. Taylor, Does higher quality early child care promote low-income chil- dren's math and reading achievement in middle childhood?. Child Development, 80 (2009), pp. 1329-1349.

DeNavas-Walt et al., 2008 C. DeNavas-Walt, B. D. Proctor, and J. C. Smith, Current population reports, P60-235, income, poverty, and health insurance coverage in the United States: 2007, Government Printing Office, Washington, DC (2008).

Dowsett et al., 2008 • C. J. Dowsett, A. C. Huston, A. E. Imes, and L. Gennetian, Structural and process features in three types of child care for children from high and low income families. Early Childhood Research Quarterly, 23 (2008), pp. 69-93.

Early et al., $2010 \bullet$ D. M. Early, I. U. Iruka, S. Ritchie, O. A. Barbarin, D. C. Winn, and G. M. Crawford, et al. How do pre-kindergarteners spend their time? Gender, ethnicity, and income as predictors of experiences in pre-kindergarten classrooms. Early Childhood Research Quarterly, 25 (2010), pp. 177-193.

Ehrle et al., 2001 - J. Ehrle, G. Adams, and K. Tout, Who's caring for our youngest children? Child care patterns of infants and toddlers (Occasional Paper Number 42), (2001), Retrieved from http:// www.urban.org/uploadedPDF/310029 occa42.pdf

Emlen et al., 2000 • A. C. Emlen, P. E. Koren, and K. H. Schultze, A packet of scales for measuring quality of child care from a parent's point of view, Portland State University, Oregon Child Care Research Partnership, Portland, OR (2000), Retrieved from http:// www.hhs.oregonstate.edu/hdfs/sites/default/files/2000-APacket-of-Scales.pdf

Forry, 2009 • N. D. Forry, The impact of child care subsidies on lowincome single parents: An examination of child care expenditures and family finances. Journal of Family Economics, 30 (2009), pp. 43-54.

Fuller et al., 1996 • B. Fuller, S. Holloway, and X. Liang, Family selection of childcare: The influence of household support, ethnicity, and parental practice. Child Development, 67 (1996), pp. 3320-3337.

Gershoff, $2003 \bullet$ E. T. Gershoff, Low income and the development of America's kindergarteners (Living at the Edge Research Brief No. 4), (2003), Retrieved from http://www.nccp.org/publications/ pub_533.html

Giannarelli and Barsimantov, $2000 \bullet$ L. Giannarelli and J. Barsimantov, Child care expenses of America's families. Assessing the New Federalism Occasional Paper Number 40, The Urban Institute, Washington, DC (2000).

Harms and Clifford, 1989 - T. Harms and R. M. Clifford, The Family Day Care Rating Scale, Teachers College Press, New York, NY (1989).

Harms et al., 1998 • T. Harms, R. M. Clifford, and D. Cryer, The Early Childhood Environment Rating Scale, Revised, Teachers College Press, New York, NY (1998).

Harms and Cryer, $1990 \bullet$ T. Harms and D. Cryer, Infant/Toddler Environment Rating Scale, Teachers College Press, New York, NY (1990).

Helburn and Howes, $1996 \bullet$ S. W. Helburn and C. Howes, Child care cost and quality. Future of Children, 62 (1996), pp. 62-82.

Hofferth, $1992 \bullet$ S. L. Hofferth, The demand for and supply of child care in the 1990s, A. Booth, Editor, Child care in the 1990s: Trends and consequences, Erlbaum, Hillsdale, NJ (1992), pp. 3-25.

Howes, $1990 \bullet \mathrm{C}$. Howes, Can the age of entry into child care and the quality of child care predict adjustment in kindergarten?. Developmental Psychology, 262 (1990), pp. 292-303.

Hu and Bentler, $1999 \bullet$ L. Hu and P. M. Bentler, Cutoff criteria for fit indexes in covariance structure analysis: Conventional criteria versus new alternatives. Structural Equation Modeling, 61 (1999), pp. $1-55$.

Johansen et al., $1996 \bullet$ A. S. Johansen, A. Leibowitz, and L. J. Waite, The importance of child care characteristics to choice of care. Journal of Marriage and the Family, 58 (1996), pp. 759-772.

Jones-Branch et al., $2004 \bullet$ J. Jones-Branch, J. Torquati, H. H. Raikes, and C. Edwards, Child care subsidy and quality. Early Education and Development, 15 (2004), pp. 327-341.

Kontos et al., $1995 \bullet$ S. Kontos, C. Howes, M. Shinn, and E. Galinsky, Quality in family child care and relative care, Teachers College Press, New York, NY (1995).

Lee and Burkam, $2002 \bullet$ V. E. Lee and D. T. Burkam, Inequality at the starting gate: Social background differences in achievement as children begin school, Economic Policy Institute, Washington, DC (2002).

Leslie et al., $2000 \bullet$ L. A. Leslie, R. Ettenson, and P. Cumsille, Selecting a child care center: What really matters to parents?. Child \& Youth Care Forum, 29 (2000), pp. 299-322. 
Li-Grining and Coley, $2006 \bullet$ C. P. Li-Grining and R. L. Coley, Child care experiences in low-income communities. Early Childhood Research Quarterly, 21 (2006), pp. 125-141.

LoCasale-Crouch et al., $2007 \bullet$ J. LoCasale-Crouch, T. Konold, R. Pianta, C. Howes, M. Burchinal, and D. Bryant, et al. Observed classroom quality profiles in state-funded pre-kindergarten programs and associations with teacher, program, and classroom characteristics. Early Childhood Research Quarterly, 22 (2007), pp. 3-17.

Loeb et al., $2004 \bullet$ S. Loeb, B. Fuller, S. L. Kagan, and B. Carrol, Child care in poor communities: Early learning effects of type, quality, and stability. Child Development, 751 (2004), pp. 47-65.

Love et al., 2002 • J. M. Love, E. E. Kisker, C. M. Ross, P. Z. Schochet, J. Brooks-Gunn, and D. Paulsell, et al. Making a difference in the lives of infants and toddlers and their families: The impacts of Early Head Start (Volume I: Final Technical Report), (2002), Retrieved from http:/ / www.mathematica-mpr.com/PDFs/ehsfinalvol1.pdf

Marshall et al., $2003 \bullet$ N. L. Marshall, C. L. Creps, N. R. Burstein, K. E. Cahill, W. W. Robeson, and S. Y. Wang, et al. Family child care today: A report of the findings of the Massachusetts Cost/Quality Study, (2003), Retrieved from http://www.abtassociates.com/reports/FCCH12 31 03.pdf

McCartney et al., $2007 \bullet$ K. McCartney, E. Dearing, B. A. Taylor, and K. L. Bub, Quality child care supports the achievement of low-income children: Direct and indirect pathways through caregiving and the home environment. Journal of Applied Developmental Psychology, 28 (2007), pp. 411-426.

Meyers and Jordan, $2006 \bullet$ M. K. Meyers and L. P. Jordan, Choice and accommodation in parental child care decisions. Community Development, 372 (2006), pp. 53-70.

Muthen and Muthen, 1998-2008 • L. K. Muthen and B. O. Muthen, Mplus user's guide, Los Angeles, CA (1998-2008).

NICHD ECCRN, 1997 • NICHD Early Child Care Research Network, Familial factors associated with the characteristics of nonmaternal care for infants. Journal of Marriage and the Family, 59 (1997), pp. 389-408.

NICHD ECCRN, 2000 - NICHD Early Child Care Research Network, Characteristics and quality of child care for toddlers and preschoolers. Applied Developmental Science, 43 (2000), pp. 116-135.

NICHD ECCRN, 2005 • NICHD Early Child Care Research Network, Child Care and Child Development: Results from the NICHD Study of Early Child Care and Youth Development, The Guilford Press, New York, NY (2005).

NICHD ECCRN, 2006 • NICHD Early Child Care Research Network, Child-care effect sizes for the NICHD study of early child care and youth development. American Psychologist, 61 (2006), pp. 99-116.

Peisner-Feinberg and Burchinal, $1997 \bullet$ E. S. Peisner-Feinberg and M. R. Burchinal, Relations between preschool children's child-care experiences and concurrent development: The cost, quality, and outcomes study. Merrill-Palmer Quarterly, 43 (1997), pp. 451-477.

Peisner-Feinberg et al., $2001 \bullet$ E. S. Peisner-Feinberg, M. R. Burchinal, R. M. Clifford, M. L. Culkin, C. Howes, and N. Yazejian, The relation of preschool child-care quality to children's cognitive and social developmental trajectories through second grade. Child Development, 72 (2001), pp. 1534-1553.

Phillips et al., $1994 \bullet$ D. A. Phillips, M. Voran, E. Kisker, C. Howes, and M. Whitebook, Child care for children in low-income: Opportunity or inequity?. Child Development, 65 (1994), pp. 472-492.
Pianta et al., 2005 • R. Pianta, C. Howes, M. Burchinal, D. Bryant, R. Clifford, and D. Early, et al. Features of pre-kindergarten programs, classrooms, and teachers: Do they predict observed classroom quality and child-teacher interactions?. Applied Developmental Science, 93 (2005), pp. 144-159.

Raikes et al., $2003 \bullet$ H. H. Raikes, B. Wilcox, C. Peterson, S. Hegland, J. Atwater, and J. Summers, et al. Childcare quality and workforce characteristics in four Midwestern states, (2003); available online from http:/ / digitalcommons.unl.edu/ccflpubs/13/

Ramey et al., $2000 \bullet$ C. T. Ramey, F. A. Campbell, M. Burchinal, M. L. Skinner, D. M. Gardner, and S. L. Ramey, Persistent effects of early childhood education on high-risk children and their mothers. Applied Developmental Science, 4 (2000), pp. 2-14.

Ryan et al., in press • Ryan, R. M., Johnson, A., Rigby, E., \& BrooksGunn, J. The impact of child care subsidy use on child care quality. Early Childhood Research Quarterly. Advance online publication.

Sachs, $2000 \bullet$ J. Sachs, Inequities in early care and education: What is America buying?. Journal of Education for Students Placed at Risk, 5 (2000), pp. 393-395.

Tout et al., $2001 \bullet$ K. Tout, M. Zaslow, A. Romano Papillo, and S. Vandivere, Early care and education: Work support for families and developmental opportunity for young children (Child Trends Occasional Paper Number 51), The Urban Institute, Washington, DC (2001).

Vandell et al., $2010 \bullet D$. L. Vandell, J. Belsky, M. Burchinal, L. Steinberg, and N. Vandergrift, \& the NICHD Early Child Care Research Network, Do effects of early child care extend to age 15 years? Results from the NICHD Study of Early Child Care and Youth Development. Child Development, 81 (2010), pp. 737-756.

Votruba-Drzal et al., 2004 • E. Votruba-Drzal, R. L. Coley, and P. L. Chase-Lansdale, Child care and low-income children's development: Direct and moderated effects. Child Development, 75 (2004), pp. 296-312.

Votruba-Drzal et al., $2010 \bullet$ E. Votruba-Drzal, R. L. Coley, C. Maldonado-Carreno, C. P. Li-Grining, and P. L. Chase-Lansdale, Child care and the development of behavior problems among economically disadvantaged children in middle childhood. Child Development, 81 (2010), pp. 1460-1474.

Weinraub et al., $2005 \bullet$ M. Weinraub, A. B. Shlay, M. Harmon, and H. Tran, Subsidizing child care: How child care subsidies affect the care used by low-income African American families. Early Childhood Research Quarterly, 20 (2005), pp. 373-392.

Whitebook et al., $1989 \bullet$ M. Whitebook, C. Howes, and D. Phillips, The national child care staffing study, Child Care Employee Project, Oakland, CA (1989).

Whitebook et al., $2007 \bullet$ M. Whitebook, F. Kipnis, and D. Bellm, Disparities in California's child care subsidy system: A look at teacher education, stability, and diversity, Center for the Study of Child Care Employment, Berkeley, CA (2007), Retrieved from http:// www.irle.berkeley.edu/cscce/wp-content/uploads/2007/01/subsidy system07.pdf

Witte and Queralt, $2004 \bullet$ A. D. Witte and M. Queralt, Child care choices of families receiving child care subsidies, Presentation at the Child Care Policy Research Consortium, Washington, DC (2004, April). 